\title{
Evolution of Residential Building in Iran based on Organization of space
}

\author{
Mazdak Irani ${ }^{1}$, Peter Armstrong ${ }^{1} \&$ Amir Rastegar ${ }^{2}$ \\ ${ }^{1}$ University of Sydney, Sydney, Australia \\ ${ }^{2}$ Politecnico di Milano, Italy \\ Correspondence: Mazdak Irani, University of Sydney, Sydney, Australia. E-mail: mazdakirani@mail.com
}

Received: June 4, 2017

Accepted: June 26, 2017

Online Published: July 21, 2017

doi:10.5539/ach.v9n2p46

URL: https://doi.org/10.5539/ach.v9n2p46

\begin{abstract}
Iranian architecture and urbanism have developed in a historical process based on the different needs of people. The evolution of traditional Iranian architecture and urbanism may be characterized by eight factors: introversion, spatial organization, function of different parts, lifestyle, construction method, communication between houses, climatic conditions, and relationship with nature. In the recent decades, however, Iranian architecture and urbanism have faced a blind imitation of foreign cultures. The majority of modern buildings do not reflect the national identity of Iranian people. This paper investigates the architectural and urban transformation in Iran based on the rearrangement of building spaces. In doing so, the paper explores the development process of major interior and exterior elements such as public entrances, private entrances, kitchens, rooms, yards and open spaces. As a conclusion, while traditional Iranian architecture attempts to preserve the national identity and meet the different needs of Iranian people, the modern architecture is a blind imitation of western cultures.
\end{abstract}

Keywords: Architectural transformation in Iran, arrangement of spaces, room, entrance, yard, open space

\section{Introduction}

Home has always been an integral part of human life. home as essential need of human being developed through history and time and that is why all civilizations have paid particular attention to home architecture. This sensitivity has gone as far as to become a national symbol in all cultures. Every nation in the world has a unique culture and identity.

More than any other art, architecture is associated with human culture. Man has always sought a safe place to for protection against environmental hazards. This vital need has remained unchanged over history. In other words, home architecture is a place where some human activities take place and is an integral part of human life (Alalhesabi \& Karani, 2013).

Many years ago, architecture used to be interconnected with man's demands and abilities. Home was a manmade place that developed based on climatic conditions and cultural norms during many generations. The traditional home was developed during this process (Shabani, Tahir, Shabankareh, Arjmandi \& Mazaheri, 2011).

With scientific and technological development, the necessities of the modern society, and ethnic and cultural gaps, the construction of houses (so-called residential units) was entrusted to architects and mass construction. These residential units are quickly built without the presence of the owner and without any consideration to climatic conditions or cultural norms. Consequently, the owners have no feeling of attachment to, or security in, such houses. This change of lifestyle involves almost all social, political and economic aspects of human life.

In Europe, architectural transformation took place more slowly reflecting a gradual change in social relations and penetrated all aspects of lifestyle. In some cases, industrial achievements replaced the housing elements. In some others, such achievements severely transformed the housing elements (Nabavi, Yahaya \& Goh, 2012).

The evolution process of traditional houses explains their architectural patterns and the impact on modern architecture, and determines the points considered in this paper in the development of modern housing in Iran.

\section{Public Access}

Considering its outside to inside welcoming nature, traditional Iranian architecture and urbanism not only tries to drag the physical person toward the inner parts of a house, but also does its utmost to thoroughly involve his soul, 
with all the senses present, into its privacy. This invitation has its roots in the introverted spirit of Iranian architecture and urbanism which has been on a quest to secure the privacy of the inner parts of a house. That is why the accessibility from public spaces of Iranian cities, as the platform of forming social life, towards inner sections of Iranian houses, as the most private living spaces, is not at all accidental. It is intentional and aims to construct an elegant harmony between movement and immovability. The overlap of the two defines the access hierarchy.

This passage from a social space into a more private one is not clear cut. It lacks any fixed or inflexible border; it is more of a series of entangled circles overlapping one on another which facilitates the transition from public to private spaces, both physically and mentally. In order for an individual to get to more private spaces inside a house, one needs to pass through the city's totally public places such as bazaars, mosques, and main streets and follow an obvious shift of perspective by walking into less major passageways that are more cramped (as semi-public places) and mostly narrow (Fig. 1). This shift of perspective enables the individual to feel more prepared to step inside private spaces. Then he would face a semi-private space. This space used to be V-shaped and resembled a semi-private space that was commonly used by residents of a house (who were usually relatives and acquaintances) to get to different rooms. Upon arrival in this space, one would have the mental preparation to enter the most private part of a house. Following a short hesitation, the individual would step toward the entrance door of the house. In the next chapter, house entrance is explained at length.

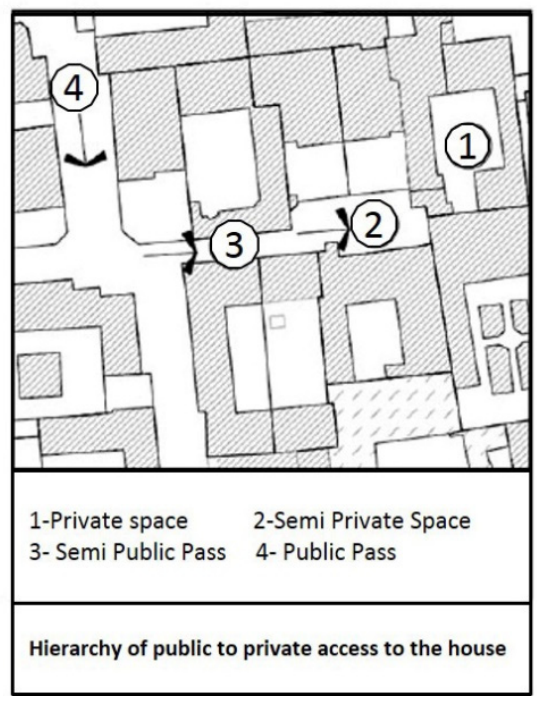

Figure 1. Master of urban planing and policy design, Politecnico di Milano

\section{Private Entrance}

Traditional houses in Iran used to be introverted and yard-oriented. They were often located in allies, lanes and other secondary roads. All houses, whether ordinary or aristocratic, were built in a traditional style in accordance with fundamental architectural principles. They normally had a brick façade and tall and simple walls without any window (Bekleyen \& Dalkiliç, 2011).

\subsection{Traditional Entrance}

A traditional entrance that was popular in Tehran and some other cities consisted of a pointed arch that covered the opening, two platforms each side of the door, a rectangular double wooden door with metal doornails and door knocker, and two brick pillars either side of the entrance opening on which arch bases were located (Javadi Amoli, 2011).

\subsection{Semi-Traditional Entrance}

In the Qajar era( 1789-1925) plan, a centre arch was widely used to cover the openings of shops, doorways and entrance spaces. In some cases, two platforms were built on two sides of the entrance and used as seats. Sometimes these platforms were too small to sit on and only had a decorative role.

\subsection{New Entrance}

In the late Qajar era, (1789-1925) non-traditional forms such as pediments, broken pediment and helmets (simple or adorned by Persian patterns), and brick works and tiling became popular in Iran. Such forms were often 
influenced by Russian architecture, arrival of Foreigners to Iran, the travel of Iranians to Europe, and construction of European embassies and buildings in Iran. These decorations were normally used in portals and were often simple pillars without prolific adornments. In certain cases, however, decorative tiles or bricks were used to adorn the pillars (Moosavi, 2011; Arjmandi, Tahir \& Shabani, 2010).

\subsection{Porch}

In the past, many entrances used to have a porch that came immediately after the entrance space. One of the applications of the porch was to divide the entrance and in certain public buildings or houses, the porch branched into two or more ways, each leading to a specific space of the building.

\subsection{Corridor}

Corridor is the simplest space of the entrance and provides access between two spaces. In some buildings, such as houses, public baths, mosques and school, the direction of the corridor changed at its centre (Kateb, 2012).

\subsection{Platform}

A raised platform was placed at each side of the door and was used as a waiting place for those who visited the owner but did not enter the house. It was also a place in which the owner talked to neighbours and visitors.

Table 1. The ratio of kitchen area to total building area in different periods

\subsection{Door Head}

\begin{tabular}{lr}
\hline Period & Ratio \\
\hline Before 1921 & 4.5 \\
$1921-1951$ & 6.5 \\
$1960 \mathrm{~s}$ & 12 \\
$1970 \mathrm{~s}$ & 11 \\
$1980 \mathrm{~s}$ & 13 \\
$1990 \mathrm{~s}$ & 13.5 \\
$2000 \mathrm{~s}$ & 13.2 \\
\hline
\end{tabular}

The door head was a decorative crescent above the door; particularly in aristocratic houses. It was the only part in the outer space of the buildings to be adorned by decorative tiles and verses of the Quran. The outer walls of the house were often made of thatch, with the door head being the only luxurious part.

\subsection{Door Knocker}

Traditional houses often had a wooden door made up of two equal parts, each having a door knocker. Women used the left knocker which produced a treble sound and men used the right one which produced a bass sound.

Figure 2 illustrates different types of entrance and Figure 3 illustrates the elements of the entrances in traditional Iranian architecture.
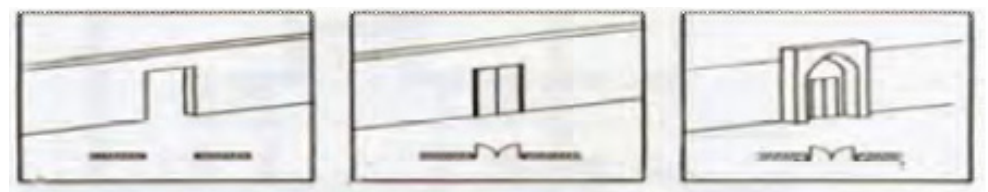

(a)
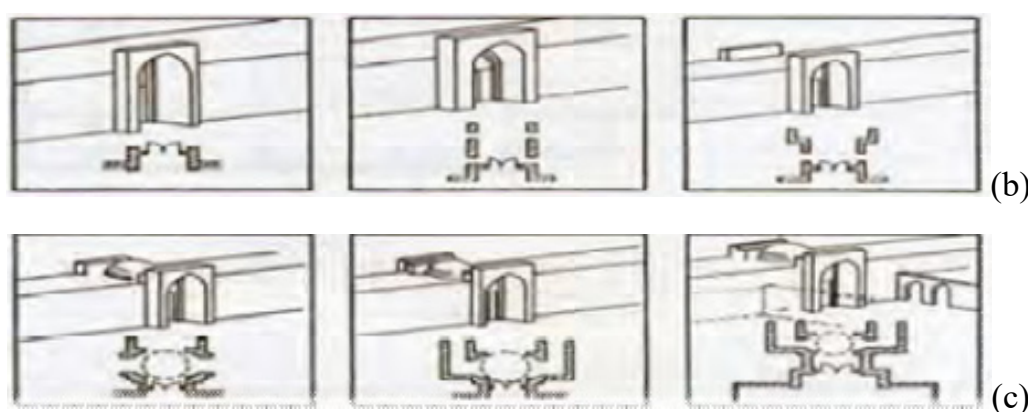

(b)

Figure 2. Different types of entrance in traditional Iranian architecture: a) simple entrance, b) entrance with prior section, and c) entrance with prior section and stoppage and division space (Kateb, 2012) 


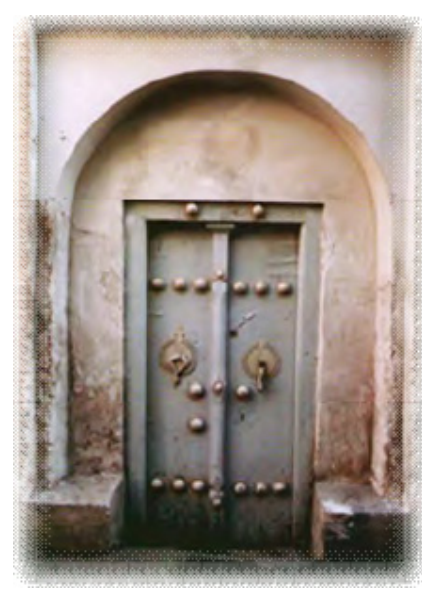

(d)

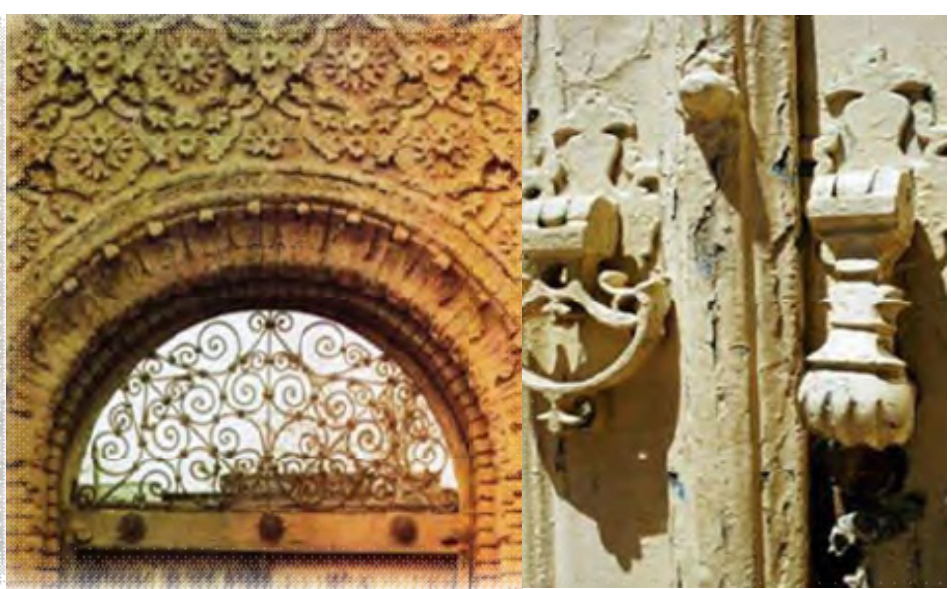

(e) (f)

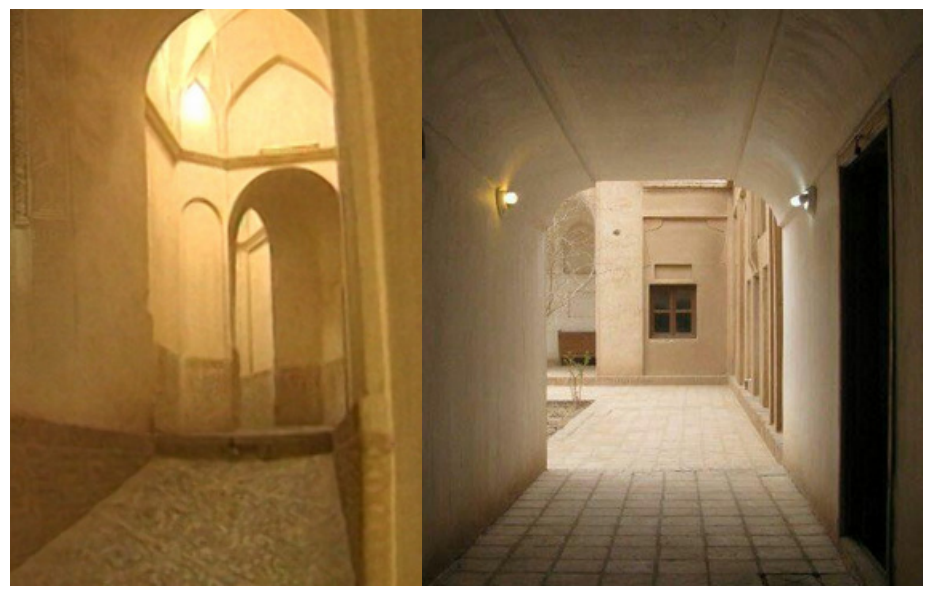

(g)

(h)

Figure 3. Different elements of entrance in traditional Iranian architecture: d) platform, e) door head, f) door knocker, g) porch, and h) corridor (Kateb, 2012).

\section{Yard and Open Space}

The hierarchical system of passages and access ways is a successful method used in traditional Iranian architecture. This method has been used to organize public and semi-private spaces and to reduce penetration by strangers (Choay, 1996). When we stand in the yard of an Iranian house, we do not see any strangers. Even the neighbouring roofs respect the privacy of the yard that offers perfect visual security (Reissi, 1996).

\subsection{Relationship with Nature}

A relationship with nature improves the relations between family members and helps them to better meet their needs (Gottlob, 1995).The relationship between humans and nature is an indicator of the balance between the world of being and the laws governing nature. Religious teaching is that there is a close relationship between humans and nature (Mirfendereski, 1995).

\subsection{Closeness to House}

Inner and outer spaces are separated by physical elements. The walls not only specify the inner space but also denote its separation from the outside. Closeness is a significant factor in the separation between inner and outer spaces. 


\subsection{The Modern Yard}

In the modern age, the population of cities increased as a consequence of industrialization. With increased urbanization, mass construction replaced the traditional architecture and industrial spaces replaced natural environments. The trend towards mass construction offered a new physical pattern which formed the architectural framework of the next generations (Cassirer, 1993; Abolghasemi, 1992). This new construction method offered similar houses based on a predefined design. This method was even used in the construction of residential complexes. From 1970 to 2000, a large number of houses were built without consideration of geographical features and typology (Fig. 4). This led to a stereotypical architecture which gave rise to various problems such as identity crisis.

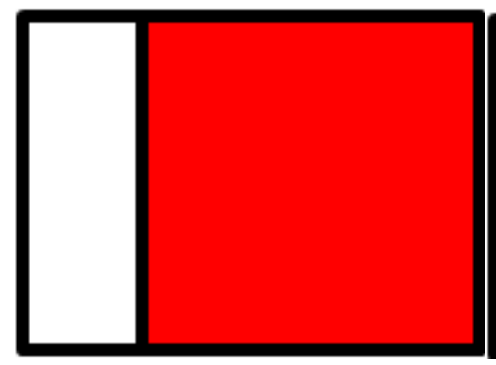

(a)

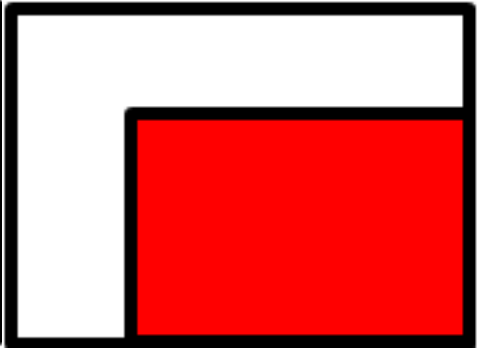

(b)

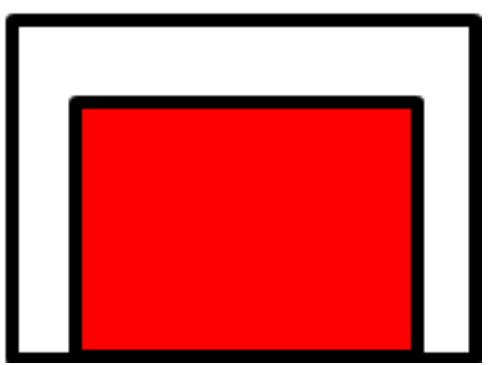

(c)

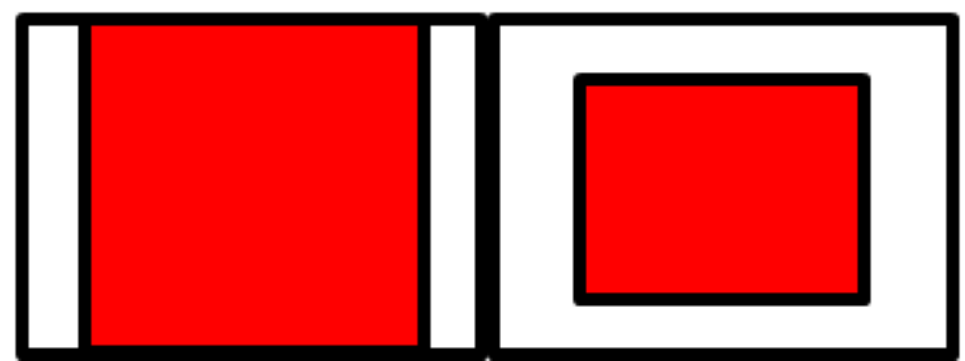

(b)

(c)

Figure 4. Typology of modern houses in terms of relationship between open and roofed areas: a) one-way yard, b) two-way yard, c) three-way yard, d) enclosed yard, c) parallel yard

\subsection{Distribution of Open Spaces in Modern Complexes}

First, we used available statistics to identify the regions with the highest number of residential complexes. Then, we visited the qualified residential complexes. After collecting the field data and analysis of the data, we determined the factors shared by the complexes and extracted the typology of the residential complexes in terms of open spaces. The statistical population consisted of the regions in which complexes had the most residential units.According to the number of licenses issued for buildings consisting of nine units and more, building construction in the northern districts of Tehran during 2001-2011 (districts 1-7) was about four times that of other districts (Wilber, 1986).

The second typological parameter was the number of units in each complex. We analysed the number of residential units in each complex using SPSS and divided the complexes into three groups: small complex (fewer than 216 units), medium complex (between 217 and 504 units) and big complex (more than 505 units).

In spite of the data contained in Figure 8, the spatial quality was still ambiguous and another parameter was needed. To solve this problem, we used a third parameter; that is, the arrangement of residential blocks in the site and the type of relationship between open and roofed areas. From the obtained plans, we divided the residential complexes into three main groups: e) scattered complexes, f) strip-like complexes, and g) centralized complexes (Fig. 5). 


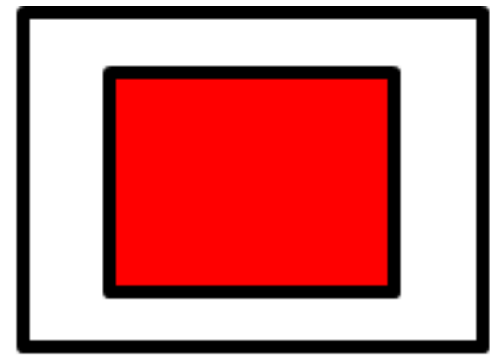

(e)

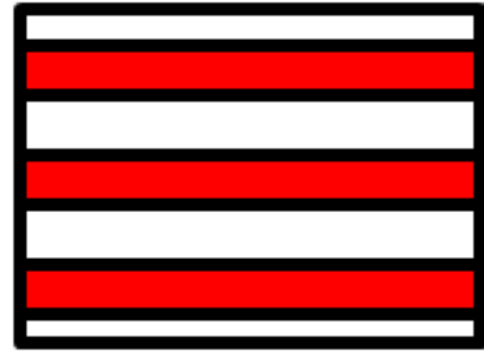

(f)

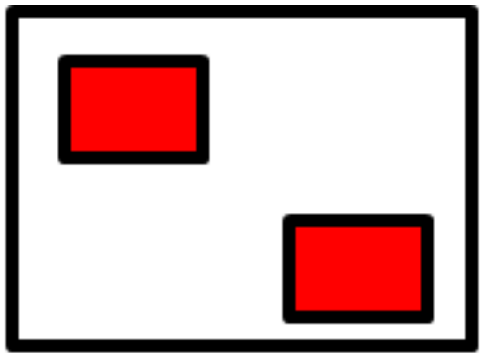

(g)

Figure 5: Various types of arrangement of residential complexes: e) centralized complex, f) strip-like complex, and g) scattered complex

The majority of residential complexes in Tehran city have scattered blocks. The residential complexes with short blocks tend to have a strip-like arrangement, but those with tall blocks tend to have a scattered arrangement. The residential complexes with tall blocks, scattered arrangement, and over 500 residential units, constitute the dominant type of arrangement in Tehran (Corbin, 1980; Durant, 1956).

\section{The Role of the Kitchen}

The kitchen is the place where the food is cooked and dishes are washed. It is also where breakfast is served and the dining table is located. The kitchen plays a vital role in home because it is continuously used by the housewife and other family members. An efficient connection between the kitchen and other spaces of the house (such as dining room and guest room) is a key factor in designing a house. Easy access, combined with visual and acoustic connection, enables these independent spaces to function properly in the house. Therefore, kitchen design should offer good functionality combined with ease and comfort (Ghamari \& Amin, 2010; Charlotte, 2009).

The internal spaces of the house are divided into: a) private spaces, b) middle spaces, and c) general spaces. The kitchen is a middle space because it is not only used by family members but is also used by guests if requested by the host (Haeri Mazandarani, 2009; Iranmanesh \& Bigdeli, 2009). Therefore, particular attention should be paid to the location of the kitchen in the house to ensure easy access between the spaces.

\subsection{The Process of Spatial Changes}

Throughout the 1900's, many changes have been made to the location of the kitchen in houses. Sometimes it has been built near the main entrance of the house so that the purchased materials can be carried directly to the kitchen. In some cases, it has been built in the middle part of the house so that it enjoyed light and ventilation. However, in the most popular arrangement, the kitchen is located near the dining room where the food is served. The connection between these two spaces is provided by a small opening on the shared wall (Moradi \& Akhtarkavan, 2008; Iranmanesh \& Bigdeli, 2009). This opening was later developed into a full door. As contemporary houses became smaller, the shared wall between kitchen and dining room was removed. Today, the removal of the shared wall between dining room and kitchen is very popular even in large buildings. It indicates the reciprocal relationship between spatial organization and lifestyle (Figure 6).

In the period before 1951, the kitchen constituted about $7 \%$ of total building area. It had a window facing the outside for lighting and ventilation purposes. The connection between the kitchen and other spaces was provided by a secondary corridor connected to the main corridor and entrance and it had a storeroom connected to both, through which raw materials were carried directly into the kitchen.

From 1961 to 1971 , kitchens constituted about $12 \%$ of total building area and had a window facing the outside. The connection between the kitchen and other spaces was provided by a corridor. The storeroom was removed from the kitchen in this period.

During 1971 to 1981 , the kitchen constituted about $11.5 \%$ of total building area. In all studied cases, the kitchen enjoys direct light indicating that at least one side of the kitchen faced an open area. The connection between the kitchen and other spaces was provided by a secondary corridor. The dining room was an independent space. In a few cases there is an opening between the kitchen and the dining room. However, spatial independence was preserved because communication was made via the opening.

In the period 1981 to 1991 , kitchens increased in size. The average size of the kitchen in the studied cases for this period is $13.25 \%$ of total building area. There is indirect lighting in a few cases, which is provided by the dining 
room or skylight. The removal of the kitchen wall is seen in almost half of the cases. In contrast to the past decade, which is characterized by a single pattern for kitchen access, several patterns were identified in the studied cases.

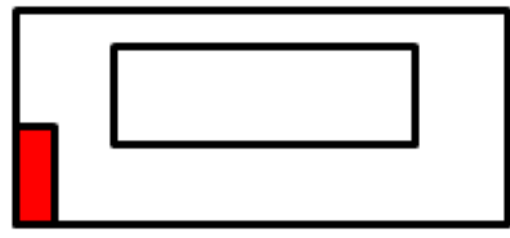

(a)

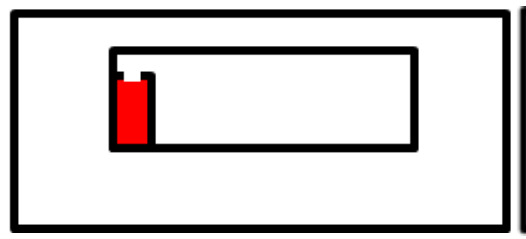

(d)

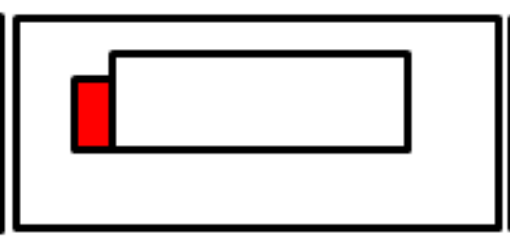

(b)

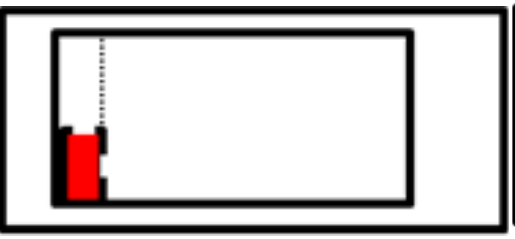

(e)

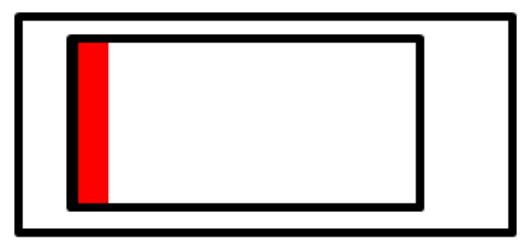

(g)

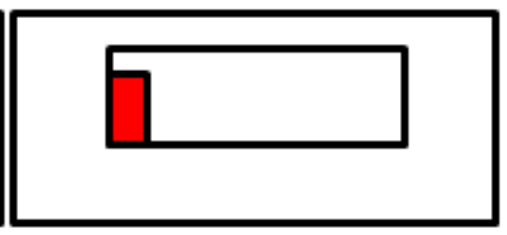

(c)

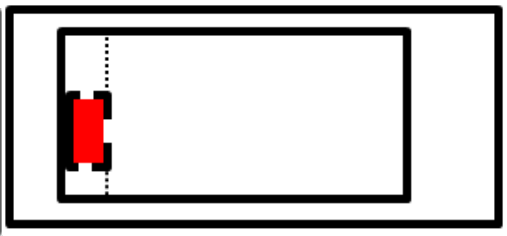

(f)

Figure 6. Development process of kitchen location: a) before 1921, b) before 1950, c) 1960s, d) 1970s, e) 1980s, f) $1990 \mathrm{~s}, \mathrm{~g}) 2000 \mathrm{~s}$

From 1991 to 2011 , kitchens constituted $13.56 \%$ of the total building area. This is not a considerable increase on the space occupied by kitchens in the previous decade. In this period, there are so many access patterns that one cannot specify a dominant pattern. The dining room loses its independence to some extent, whether by the lack of a kitchen wall or by a shared door between the kitchen and dining room. The significant point in this period is that, except for a few cases, there is no shared wall between the kitchen and dining room. This is the dominant pattern in this period. The difficult connection with yard and open space remained a problem in this decade (Gholigani Moghadam, 2005; Mahmoodi, 2005).

Table 1 contains the ratio of kitchen area to total building area in different periods based on the studied cases:

In the period before 1921 , kitchens constituted $5 \%$ of total building area. Generally, the building was divided into two sections: welfare and service sections. The kitchen was located in the upstairs service section. Access was possible through the yard and ventilation and lighting were provided through the ceiling. The storeroom, used to store raw materials, was located at the entrance part of the kitchen (Gholigani Moghadam, 2005; Mahmoodi, 2005).

\section{Rooms}

In traditional architecture, the name of each room referred to the number of doors from the yard to the room, e.g. three-door room, five-door room and seven-door room (Belakehal, Tabet Aoul \& Bennadji, 2004). The three-door room was often the private room or bedroom. The word Khaneh, which is now a common word, used to be the name of a room. The private room was called Vostakh, Gostakh or Vosagh (Mahmoodi, 2004). In designing the house, all rooms were measured based on the size of a typical Iranian man. The height of room was determined based on a man of average stature (Sheikh, 2004).

\subsection{Traditional Houses}

In traditional houses, the floors of rooms were above the yard surface and indicated the importance and dignity of the room. Everybody had to take their shoes off before entering the room. In summer, the raised floor prevented the 
penetration of water. The floor was covered by $20 \mathrm{~cm}$ bricks and the wall had a niche which held certain objects. The wall was covered by plaster and the door was made of wood. The upper part of the door was often adorned by coloured glasses (Ghobadian, 2003).

\subsection{Qajar Era (1789-1925)}

In this era, houses often had a corridor around the stairway which was faced by lateral rooms. A large room, called Tonbi, was located at the middle of the northern part of the building and small rooms (three-door rooms and bedrooms) were located at the other sides. Tonbi rooms had coloured and latticed sash windows and bedrooms had ordinary windows. The Tonbi's windows were often arch-like but those of the bedrooms were rectangular. The building faced the south so that the main spaces, such as dining room and bedroom, enjoyed sufficient light in different seasons. The windows were made of wood and the walls were made of brick. Windows were big and were located at the top of the wall. The rooms received the light from the south. The walls were decorated by plasterwork. The rooms often had no terrace but sometimes there was a porch. The only important spaces in the secondary path were three-door rooms which were used as dining rooms or bedrooms. Because of the importance of privacy, the rooms faced the yard. In this period, the rooms had semicircular arches and three-door rooms were changed to two-door rooms. In some houses, there are semicircle arches and terraces (Grabar \& Ettinghausen, 2003; Ratti, Raydan \& Steemers, 2003).

- Fronts: In this period, northern and western fronts had the first and second priorities respectively (houses of Haj Sheikh, Mashrootiat and Mojtahedi). The Alavi house is the only one to have an eastern front, with the western part of land dedicated to the yard.

- Building orientation: The buildings face the south in order to use sufficient sunlight in all seasons.

- Arrangement of entrance in relation to neighbourhoods: The entrance faced a space where there was no neighbour and was limited to a passage. The same was true in the houses with two entrance doors.

- Arrangement of entrance in relation to main and secondary axes: The entrance was located at the sides of the main and secondary axes depending on the importance of privacy of the internal spaces.

- Spaces located in the main axis of the building: The main spaces, such as Tonbi, spring house and porch, were located on the main axis of the building.

- Spaces located on the secondary axis: Only three-door rooms were located on the secondary axis.

- Entrance: An entrance space existed only in certain houses. The entrance often had a geometrical and symmetrical shape.

- External yard: In houses with two internal and external yards, the external yard was located in the south. In houses with a single yard, the yard functioned as the external yard.

\subsection{Pahlavi I (Reza Shah - 1925-41)}

The architecture of this period is characterized by the rooms facing the allies and streets because of the rise of extroversion (however, the privacy of houses was preserved by the height of windows). The semicircle arches were increasingly used in this period. The windows had a brick frame with diverse designs. Western and eastern rooms were deprived of sufficient light. Access to rooms was provided by a corridor. The rooms facing the alley or street were not immune from noise, dust and air pollution. Certain linear-vertical elements were used on the windows to augment their beauty. Balconies were increasingly used at the front of the windows (balconies used to be specific to kings). Moreover, metal fences began to be used in the windows (Kristian sen, 1999; Karimi, 1997).

\subsection{Pahlavi II (Mohammad Reza Shah 1941-79 and Post Islamic Revolution Era)}

In this period, the rooms were characterized by their furniture. For example, bedrooms could not be changed into a dining room, and vice versa. The rooms were distinguished not only by their sizes and dimensions but also by their specific furniture. Today's rooms no longer have the functionality and spatial diversity of the past. In modern architecture, bedrooms can only be used as bedrooms, with only its capacity being changeable (Fig. 7). For example, a single bedroom may be changed into a double bedroom, but it may not be changed into a dining room. The same is true for dining rooms (Ahmadi, 1996; Karimi, 1997).

Pahlavi I Architecture:

- Traditional architecture

- International style

- Idealism Expressionism 
Pahlavi II Architecture:

- Ecological architecture

- Modernist architecture

- Iranian neoclassicism

- Eclectic architecture

- Sublime modernist architecture

- Construction of buildings by contractors

- Modern mass construction

Architectural features of the post Islamic Revolution era may be classified into eight groups:

- Revival of traditional Iranian architecture

- Ecological architecture

- Inclination to western architectural styles (e.g. residential apartments designed by commercial architects)

- Persistence of sublime modern architecture (this inclination may be seen in the architecture of residential buildings, apartments, commercial and administrative high-rise buildings, and public and services buildings)

- Combination of Iranian architecture with modern architecture and technology

- Inclination to high technology

- Inclination to neo-modern architecture

- Computer-aided architecture (Callins, 1996).

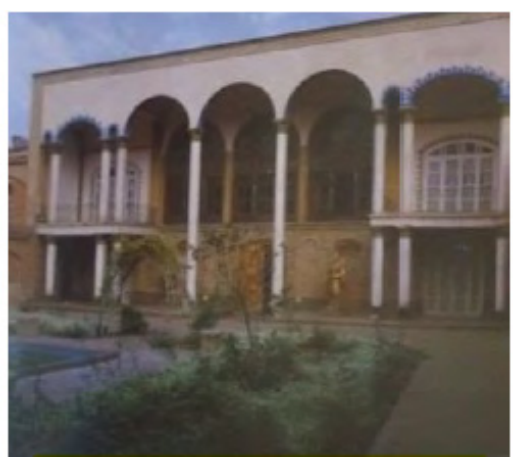

(a)

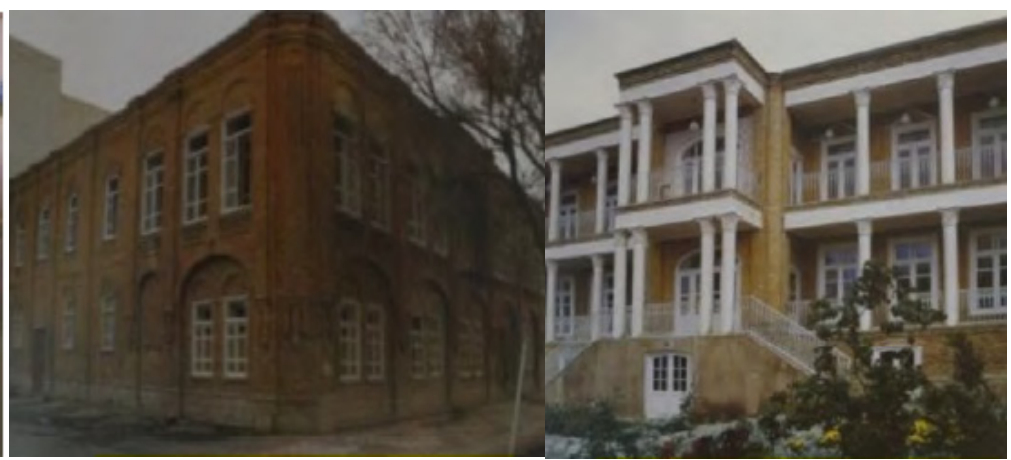

(b) (c)

Figure 7. Rooms in different eras: a) Qajar, b) Pahlavi I, c) Pahlavi II

\section{New Small Houses in Metropolises}

Because of high costs in metropolises like Tehran, architects have to design small houses. Such houses are based on the following principles:

Separation of spaces: Proper definition and separation of spaces is one of the duties of interior designers. Each space is used by one person or group. The territory of these spaces is specified by proprietary behaviours and placement of furniture.

Distance: In all situations, the distance between individuals is rarely stochastic or customized. Iranians have a shared understanding of acceptable distance between individuals; Eastern cultures accept less distance than western cultures do.

Circulation: Circulation in small houses is affected by the foregoing features. Sufficient distance for circulation is a requisite to mental peace and tranquillity; nobody likes to touch the body of another person when passing by. 
Hierarchy: Entering a private space needs some preparedness in advance. Such preparedness may be satisfied in different ways, such as placement of a public space before the private one. In this way, the individual has to pass a public space to reach the private space. Such preparedness should be available even in small houses.

Light: Light plays a vital role in the happiness of inhabitants. A room does not seem perfect without sufficient light and Insufficient light may result in psychological problems.

\section{Single Buildings}

Living a single life is an ever-increasing trend in Tehran. Generally, there are three types of single-specific buildings:

\subsection{Corridor Buildings}

In this pattern, the rooms are located at two sides of a long corridor. Bathroom, toilet and kitchen are outside the rooms and are shared by all individuals. In these buildings, there is no hierarchy between the rooms as the private territory and the corridor as the semi-public territory. Other spaces belong to the semi-public territory. Since the majority of spaces in such buildings do not offer the feeling of ownership, individuals tend to lose the feeling of attachment and responsibility and consequently do not observe the principles of good hygiene.

\subsection{Cluster Buildings}

In this pattern, each cluster has its own bathroom, toilet and kitchen. These spaces belong to the semi-private territory because they are specific to a single cluster and others are not allowed to use them. The spaces outside the clusters are part of the semi-public territory. These buildings offer a higher level of hierarchy compared to corridor-based buildings.

\subsection{Suites}

In this pattern, each room has a separate dining room, bathroom, toilet and kitchen (Arjmandi, Tahir \& Shabani, 2010). Privacy is a process which requires a balance between accessibility and aloneness (Javadi Amoli, 2011). In this pattern, not only the bedroom but also dining room, kitchen, bathroom and toilet belong to the private territory because they are only used by the owner of the suite.

Fig. 8 shows that suites offer the best social stability compared with other patterns. Corridor building offers the lowest social stability and cluster building offers average social stability.

\subsection{Introversion}

In traditional architecture, the privacy of house was as important as homeland and identity. Houses had internal and external borders so that strangers could not see the inside. The introversion may be explained by the hot and dry climate and the cultural norms of Iranian people (Mahmoodi, 2004). Besides, there was no border between family members and all lived in a shared room.

However, the present Iranian architecture does not pay attention to introversion and privacy of houses. The possibility of being seen by strangers has ruined the mental security of families. Besides, the separation between the rooms of parents and children has diminished the emotional ties between family members.

\subsection{Spatial organization and performance of home parts}

Because of the change to spatial organization, non-architectural language has dominated the majority of house design. When we arrive at a modern house, we cannot find the spaces we are looking for. At once, we will see all the elements which form the spaces of modern houses; everything is predictable. If the host does not lead us, or if the sofa is far away from us, there is no place to go. We are led by objects. The doors appear only when they are closed, because there is no entrance space. When the doors are closed, it is very difficult to distinguish between kitchen, bathroom, toilet and even the exit door. We might be led to the kitchen by the smell of food or to toilet by the sound of the cistern. The windows are specified by the curtains hanging on the wall rather than by the visions they should allow (Iranmanesh \& Bigdeli, 2009).

\subsection{Lifestyle}

Living in the modern houses differs from that in large traditional houses such as Borojerdi or Tabatabaei houses of Kashan City in the Qajar era. These houses had a lot of parts and facilities such as bathrooms, cisterns, terraces, several large kitchens, storerooms, woodsheds, several yards, guest rooms and tall walls. With the growth of the construction and decoration industry, walls were eliminated and traditional styles were replaced by open rooms. The presence of windows on the external sides of the house increased the diversity of façade and enhanced the extroversion. 

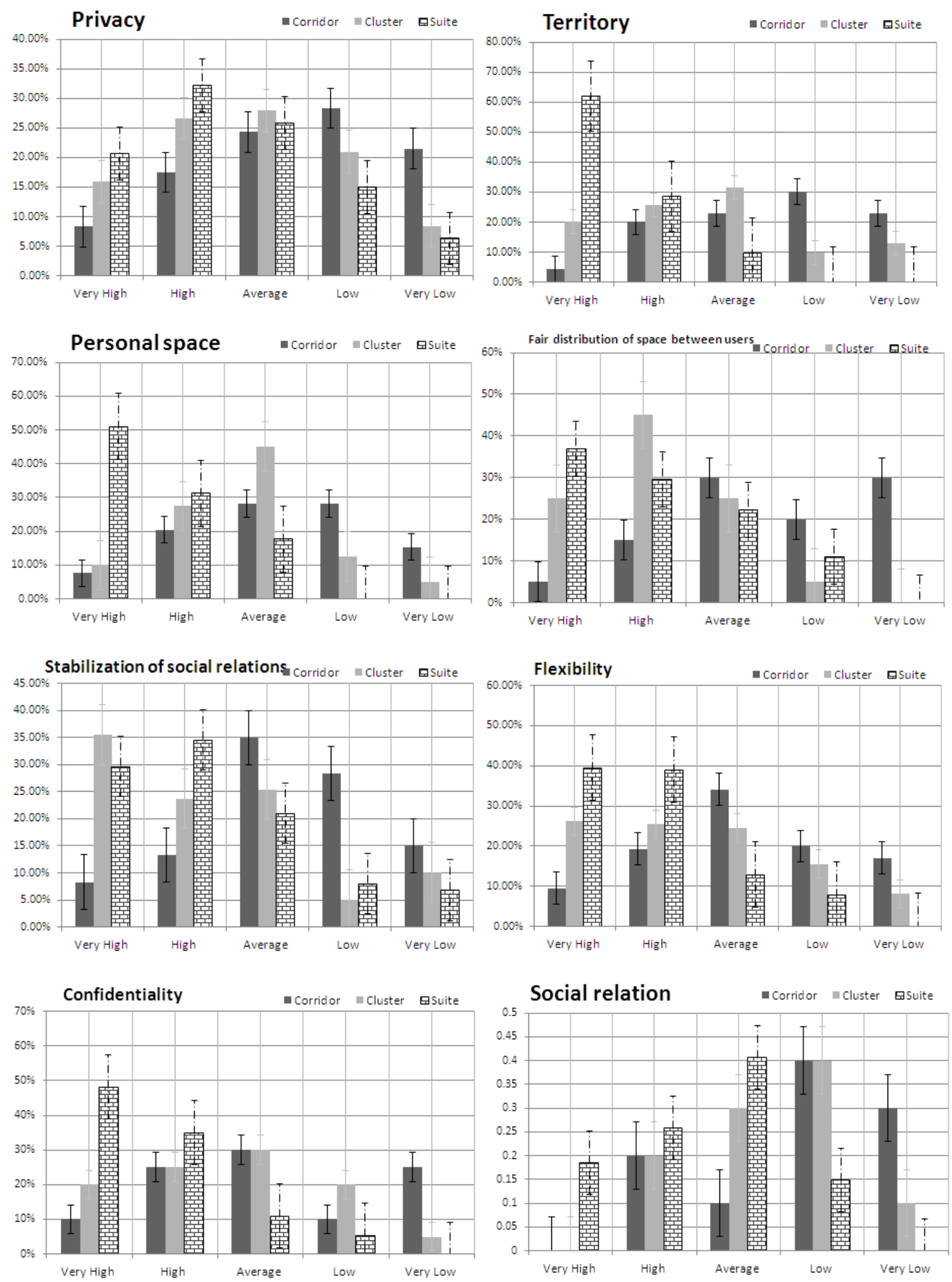


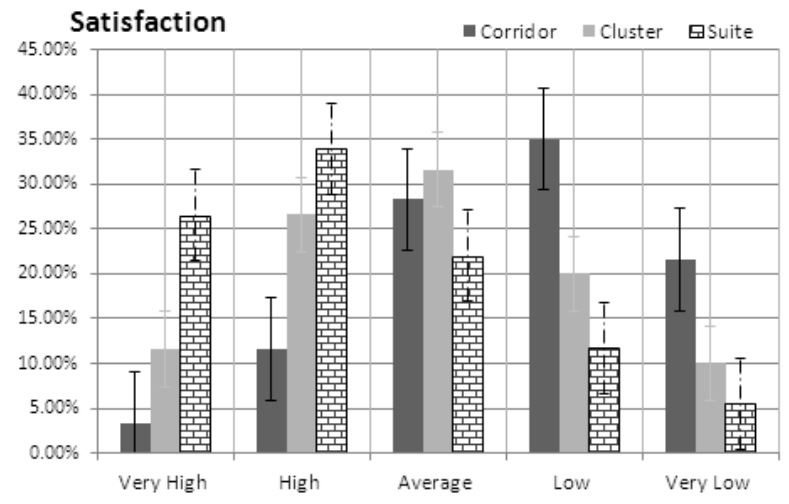

Figure 8. New small house parameters

\subsection{Construction method}

In the past, architects did not distinguish between the stability and beauty of the buildings. Experience had taught them the right sizes for different parts of the building. Using various gauges, they managed to combine stability, beauty and diversity.

\subsection{Communication between houses}

The communication between houses depends on how the buildings are organized. With the rise of capitalism and the change of lifestyle, houses gradually changed from horizontal villas to vertical buildings (Cassirer, 1993).

\subsection{Climatic Conditions}

Because of climatic conditions, such as the direction of sunlight and wind, Iranian architects used three construction methods: Rasteh, Esfahani and Kermani. In order to overcome excessive heat and cold, they utilized efficient methods such as double roofs, sunlight blockers, small coloured glasses, and shadowing technique by making different levels, even in decorations.

\subsection{Relationship with Nature}

Pirnia's definition of an Iranian house is full of terms and expressions which imply the relationship between house and human on the one hand and the relationship between house and nature on the other. The abundance of these terms denotes the diversity and richness of the relationship between humans and the surrounding environment. While these relationships are diverse, they all evoke the centrality of humans in the surrounding nature (Javadi Amoli, 2011). Consequently, all elements of Iranian traditional architecture are closely associated with social identity. Table 2 represents the role of each parameter of Iranian architecture in the preservation of national identity, which should be taken into consideration in today's architecture.

Table 2. The role of parameters of Iranian architecture in the preservation of national identity

\begin{tabular}{|c|c|c|c|c|c|}
\hline \multirow[b]{2}{*}{$\begin{array}{c}\text { Parameters of Iranian } \\
\text { Architecture }\end{array}$} & \multicolumn{5}{|c|}{ Components of National Identity } \\
\hline & $\begin{array}{c}\text { National values and } \\
\text { norms }\end{array}$ & Cultural heritage & National symbols & Geographical features & Religious beliefs \\
\hline Repetition of past patterns & & $\mathrm{X}$ & $\mathrm{X}$ & & \\
\hline The use of symbols & $\mathrm{X}$ & & $\mathrm{X}$ & & $\mathrm{X}$ \\
\hline Local architecture & & & & $\mathrm{X}$ & \\
\hline Adornments & $\mathrm{X}$ & $\mathrm{X}$ & $\mathrm{X}$ & & $\mathrm{X}$ \\
\hline Social relations & $\mathrm{X}$ & & & $\mathrm{X}$ & $\mathrm{X}$ \\
\hline Avoidance of frivolity & $\mathrm{X}$ & & & $\mathrm{X}$ & $\mathrm{X}$ \\
\hline Introversion & $\mathrm{X}$ & & & $\mathrm{X}$ & $\mathrm{X}$ \\
\hline Stability & & & & $\mathrm{X}$ & \\
\hline Self-sufficiency & $\mathrm{X}$ & & & $\mathrm{X}$ & $\mathrm{X}$ \\
\hline
\end{tabular}




\section{Conclusion}

Throughout history, Iranian artists and architects have demonstrated their great abilities by building magnificent historical sites. Iranian architecture has developed as a process reflecting the different needs of people. In the recent decades, however, Iranian architecture has faced a blind imitation of foreign cultures. The beginning of this trend may be attributed to the age of Nasereddin Shah, when western architecture arrived in Iran and gradually replaced the traditional Iranian architecture (Mahmoodi, 2005). The evolution of traditional Iranian architecture may be characterized by seven factors: introversion, spatial organization, performance of different parts, lifestyle, construction method, communication between houses, climatic conditions, and relationship with nature.

\section{References}

Abolghasemi, L. (1992). Iranian Architecture in the Expert point of View. Abadi Journal, No.19, MHUP.

Ahmadi, B. (1996). Truth and Beauty, Lectures on the Philosophy on Art, Nashre Markazi, Pub.

Alalhesabi, M., \& Karani, N. (2013). Effective Factors in Housing Transformation from the Past to the Future. Rural Housing and Environment Journal, issue 141, Tehran, Cheshmeh Press

Arjmandi, H., Tahir, M., \& Shabani, M. (2010). Application of Transparency To Increase Day Lighting Level Of Interior Spaces In The Dwelling Apartments In Tehran-A Lesson From Iranian Traditional Architecture. Editorial Board/Sidang Editor.

Bekleyen, A., \& Dalkiliç, N. (2011). The influence of climate and privacy on indigenous courtyard houses in Diyarbakhr, Turkey. Scientific Research and Essays, 6(4), 908-922.

Belakehal, A., Tabet Aoul, K., \& Bennadji, A. (2004). Sunlighting and daylighting strategies in the traditional urban spaces and buildings of the hot arid regions. Renewable energy, 29(5), 687-702. http://dx.doi.org/ 10.1016/j.renene.2003.09.001.

Callins, P. (1996). Changing Ideas in Modern Architecture, Hossein, Hassanpour, trans. Ghatre, Pub.

Cassirer, E. (1993). Philosophy of the Enlightenment, Trans. Naiaf Daryabandary, Kharazme, pub.

Gottlob, F. (1995). Thoughts in Logical Investigations Trans. Yousof Sani, Arganon, A Quarterly Journal of Philosophy, Literature and Humanities, Vol.2/ No. 7\&8/ Fall\& Winter

Choay, F. (1996). L Urbanisme Utopies et Realites, une Anthologic, Trans. Seyed Mohsen Habibi, Tehran Universit.

Charlotte, B. P. (2009). Kitchen Design. Translated by Shahi, Mohammadreza, Yazda Pub., Tehran.

Corbin, H. (1980). Philosophie Iranienne et Philosophie Comparee, Trans. S.J. Tabatabai-Nejad, Tus, Pub.

Durant, W. (1956). A Story of Civilization, (part1, our oriental Heritage), PP. 373-375.

Ghamari, K., \& Amin M. (2010). A New Look at Kitchen Design. Architecture and Culture, $12^{\text {th }}$ year, issue 40, p. 82.

Ghobadian, V. (2003). Theories and Concepts in Contemporary Western Architecture, Cultural Research Bureau.

Gholigani Moghadam, N. (2005). Historiology of the Architecture of Iran, Tehran University

Grabar, O. \& Ettinghausen, R. (2003). The Art and Architecture of Islam, Azhand, Ya. Trans.samt.

Mahmoodi, A. S. (2005). Thought in Designing, in: Proceedings of The Second Conference on Architectural Education, Tehran University

Haeri Mazandarani, M. R. (2009). House, Culture, Nature; Investigation of Architecture of Traditional and Modern Houses for the Codification of House Design Process and Parameters. Urbanization and Architecture Research Center, Tehran.

Iranmanesh, N., \& Bigdeli, E. (2009). Climatic design \& low carbon city regarding the traditional, experiences Climatic design \& low carbon city. Paper presented at the 45th ISOCARP Congress.

Javadi Amoli, A. (2011). The various schools of humanity, Qom Press

Kateb, F. (2012). Architecture of Iranian Houses ( $2^{\text {nd }}$ ed.). Endowment and Charity Affairs Pub., Tehran

Karimi, K. (1997). The Spatial Logic of Organic Cities in Iran and the United Kingdom Mahmoodi, A.S. (2004) Design Thinking, The Interactive Model of thinking and Design, in Journal of Faculty of Fine Arts, No.20, Tehran University.

Kristian sen, A. (1999). Iran in Sasanian period, Tehran Sedaye moaser Press 
Mirfendereski, M. A. (1995). Iranian Architecture in the Expert point of View, Abadi journal, No.19, HHUP.

Moosavi, M. (2011). An Analysis to Historic Roots of Climatic Design in Ancient Architecture of Central Zone of Iran. 2nd International Conference on Humanities, Historical and Social Sciences, IACSIT Press, Singapore vol.17.

Moradi, A. M., \& Akhtarkavan, M. (2008). Sustainable architecture in the hot, arid and sunny regions of Iran. Architect Engineering Special Issue, 19(6), 21-29.

Nabavi, F., Yahaya, A., \& Goh, A. T. (2012). Daylight and Opening in Traditional Houses in Yazd, Iran. http://www.plea2012.pe/pdfs/T08-20120129-0036.pdf.

Ratti, C., Raydan, D., \& Steemers, K. (2003). Building form and environmental performance: archetypes, analysis and an arid climate. Energy and Buildings, 35(1), 49-59. http://dx.doi.org/10.1016/S0378-7788(02)00079-8

Reissi, M., (1996). A study on the Zorasterian houses, Shahid beheshti Master thesis.

Shabani, M. M., Tahir, M. M., Shabankareh, H., Arjmandi, H., \& Mazaheri, F. (2011). Relation of cultural and social attributes in dwelling, responding to privacy in Iranian Traditional House. e-BANGI: Jurnal Sains Sosial dan Kemanusiaan, 6(2), 273-287.

Sheikh, Z., (2004). Comparison of Traditional and Modern Architectures. Guiding Professor: Mohammad Sadegh Farbod, Master Thesis in Anthropology, Islamic Azad University, Tehran

Wilber, D. N. (1986). The Architecture of Islamic Iran: The Ilkhanid Period, Trans: Abdollah Faryar, Elmi\& Farhangi, Pub.

\section{Copyrights}

Copyright for this article is retained by the author(s), with first publication rights granted to the journal.

This is an open-access article distributed under the terms and conditions of the Creative Commons Attribution license (http://creativecommons.org/licenses/by/4.0/). 